Research Article

\title{
Analisis Teknik Penerjemahan pada Abstrak Jurnal IJAI 6(1)
}

\author{
Ismail Yusuf Panessai ${ }^{1}$, Dedy Iskandar ${ }^{1}$, Afriani $^{1}$, Pratiwi $^{2}$, Eddy Effendi ${ }^{1}$ \\ ${ }^{1}$ Program S1 Sastra Inggris Bidang Minat Penerjemah, Fakultas Ilmu Sosial dan Ilmu \\ Politik, Universitas Terbuka. Tanggerang, Indonesia. \\ ${ }^{2}$ Universitas Andalas, Indonesia.
}

Article History
Received:
02.01 .2021
Revised:
19.01 .2021
Accepted:
08.02 .2021
*Corresponding Author:
Ismail @ Ismail Yusuf
Panessai (1027087604)
Email:
ismailyusuf.panessai@yahoo.
com

This is an open access article, licensed under: $\mathrm{CC}-\mathrm{BY}-\mathrm{SA}$
Abstract: Penerjemahan adalah mengirimkan tindakan analitis terhadap teks sumber (TSu) untuk dialihbahasakan kedalam teks sasaran (TSa) yang sepadan sehingga menghasilkan terjemahan yang baik dan dapat di mengerti oleh pembaca. Penerjemahan tidak hanya mengubah kata, tetapi juga mentransfer kesepadanan budaya dengan budaya bahasa $\mathrm{TSu}$ dan penerima bahasa tersebut dengan sebaik-baiknya. Salah satu naskah yang selalu menggunakan proses penerjemahan adalah abstrak. Abstrak bertujuan untuk memberikan gambaran umum tentang isi sebuah tulisan karya ilmiah. Tujuan penelitian ini adalah untuk mendeskripsikan proses penerjemahan yang dilakukan pada teks sumber (TSu) ke dalam teks sasaran (TSa) untuk menghasilkan terjemahan yang sepadan dan juga metode atau teknik yang muncul dalam penerjemahan teks sumber (TSu) ke dalam teks sasaran (TSa). Dari penelitian yang dilakukan dapat menunjukkan bahwa dalam proses penerjemahan yang dilakukan pada teks sumber ( $\mathrm{TSu}$ ) ke dalam teks sasaran (TSa) harus mempertimbangkan faktor-faktor yang terkandung di dalam teks tersebut agar mendapatkan hasil terjemahan yang sepadan dan dapat difahami dengan baik oleh pembaca. Faktor utama yang sangat mendukung adalah bahwa penerjemah harus melihat istilah-istilah dalam $\mathrm{TSu}$ dan memahami penggunaan istilah tersebut sehingga penerjemah bisa dengan mudah menerjemahkan naskah TSu ke dalam TSa. Selain itu, teknik penerjemahan yang banyak digunakan dalam kedua naskah adalah teknik transposisi, teknik meminjam kata baik murni maupun dengan perubahan serta teknik adaptasi dan calque.

Kata Kunci: Abstrak, Jurnal, Kuplet, Teknik Penerjemahan, TSu $\approx$ TSa.

\section{Analysis of Translation Techniques in the Abstract of IJAI 6(1)}

Abstract: Translation is sending analytical actions to the source text (TSU) to be translated into an equivalent target text (TSA) so as to produce a good translation and can be understood by the reader. Translation not only changes the word, but also transfers the cultural correspondence to the culture of the $\mathrm{TSu}$ language and its recipients as best as possible. One of the texts that always uses the translation process is an abstract. Abstract aims to provide an overview of the contents of a scientific paper. The purpose of this research is to describe the translation process carried out on the source text (TSu) into the target text (TSa) to produce an equivalent translation and also the methods or techniques that appear in translating source text ( $\mathrm{TSu}$ ) into target text (TSa). From the research conducted, it can show that in the process of translating the source text (TSU) into the target text (TSa) must consider the factors contained in the text in order to get a translation result that is commensurate and can be understood well by the reader. The main factor which is very supportive is that the translator must see the terms in TSu and understand the use of these terms so that the translator can easily translate the TSu script into TSa. In addition, the translation techniques that are widely used in the two texts are transposition techniques, techniques for borrowing words both pure and with changes as well as adaptation and calque techniques.

Keywords: Abstract, Couplet, Journal, Translation Technique, TSu $\approx$ TSa. 


\section{Pendahuluan}

Penerjemahan berperanan penting dalam sebuah komunikasi. Terjemahan merupakan media untuk memindahkan pengetahuan atau informasi. Terjemahan merupakan jembatan yang menghubungkan orang-orang dari berbagai bahasa dan budaya. Dengan menggunakan terjemahan, orang dapat belajar dan memahami bahasa dan budaya lain. Penerjemahan tidak hanya sekedar mengubah kata, tetapi juga mentransfer kesepadanan budaya dengan budaya bahasa TSu dan penerima bahasa tersebut dengan sebaik-baiknya [1]. Terjemahan yang lebih baik harus diterima oleh semua orang dalam logika dan berdasarkan fakta; Dengan demikian, pesan yang terkandung dalam teks sumber (TSu) dapat memuaskan pembaca teks sasaran (TSa) dengan informasi di dalamnya.

Salah satu naskah yang selalu menggunakan proses penerjemahan adalah adalah abstrak. Artikelartikel di jurnal selalu dimulai dengan abstrak. Ini adalah ringkasan singkat dari artikel penelitian, tesis, review dan sering digunakan untuk membantu pembaca dengan cepat memastikan tujuan makalah. Abstrak dapat bertindak sebagai entitas yang berdiri sendiri, bukan sebagai makalah penuh. Panjang abstrak biasanya berkisar dari 100 hingga 500 kata, tetapi jarang lebih dari satu halaman. Abstrak bertujuan untuk memberikan gambaran umum tentang isi sebuah tulisan karya ilmiah.

Abstrak adalah ringkasan singkat dari poin-poin terpenting dalam sebuah karya ilmiah. Day [2] menyatakan bahwa abstrak adalah karya versi mini. Abstrak memungkinkan penulis atau penerjemah untuk tetap mengikuti perkembangan literatur ilmiah yang sangat banyak. Ini adalah ringkasan singkat dari artikel penelitian, tesis, review, prosiding konferensi atau analisis mendalam tentang subjek tertentu dan sering digunakan untuk membantu pembaca dengan cepat mendapatkan tujuan makalah. Abstrak selalu muncul di awal naskah.

Secara umum diketahui bahwa menerjemahkan dari bahasa sumber ke bahasa target sangat sulit bagi mereka yang berlatar belakang bukan dari jurusan bahasa Inggris [3] [4] [5].

Penerjemah yang menerjemahkan abstrak dari Bahasa Inggris ke Bahasa Indonesia dan Bahasa Indonesia ke Bahasa Inggris harus menguasai dengan baik struktur dan teknik-teknik penerjemahan [4] [6]. Dalam penelitian ini akan dibahas tentang teknik penerjemahan yang digunakan untuk proses penerjemahan pada naskah Abstrak Jurnal Internasional IJAI 6(1)

\section{Studi Pustaka}

\subsection{Definisi Penerjemahan}

Nida dan Taber [7] menyatakan bahwa proses menerjemahkan terdiri dari mereproduksi dalam bahasa reseptor padanan alami terdekat dari pesan bahasa sumber, pertama dalam hal makna dan kedua dalam hal gaya.

Selain itu disebutkan bahwa bahwa terjemahan adalah menerjemahkan makna suatu teks ke dalam bahasa lain sesuai dengan maksud pengarangnya [8]. Secara bahasa, penerjemahan muncul sebagai ruang lingkup yang signifikan untuk mengatasi batas bahasa, yang membuat proses komunikasi menjadi lebih baik [9]. Saat ini, terdapat berbagai macam tulisan dengan bahasa Inggris sebagai bahasa sumber (TSu) yang telah diterjemahkan ke dalam bahasa sasaran (TSa) di berbagai negara, termasuk Indonesia.

\subsection{Teknik Penerjemahan}

Beberapa teknik penerjemahan yang diperkenalkan oleh Newmark [8], Nida \& Charles [9], Molina \& Albir [10], Machali \& Rohayah [11] dan Nababan \& Rudolf [12], antara lain:

- Teknik harfiah

- Teknik peminjaman alamiah

- Teknik tranferensi

- Teknik calque

- Teknik peminjaman murni

- Teknik transposisi

- Teknik modulasi

- Teknik penghilangan

- Teknik eksplisitasi

- Teknik penambahan

- Teknik deskriptif 
1. Harfiah (literal translation)

Terjemahan Literal menerjemahkan ekspresi dalam TSu dalam kata kata-kata ke TSa sehingga aspek TSu dapat dipertahankan dalam TSa walaupun terkesan terikat dengan TSu (beroreientasi pada $\mathrm{BSu}$ ).

TSu: the market for foreign-currency exchange

TSa: pasar pertukaran valuta asing

2. Peminjaman alamiah (naturalized borrowing)

Meminjam menggunakan kata atau frasa saat menerjemahkan bahasa sumber ke dalam bahasa target dengan melakukan perubahan yang tidak menghilangkan unsus-unsur TSu.

TSu: investment

TSa: investasi

3. Tranferensi

Penerjemah yang mempertahankan konstruksi TSu dan sering terperangkap pada konstruksi TSu yang relative komplek yang menyebabkan teks terjemahan akan terbaca sebagai sebuah terjemahan atau sedikit kaku atau terkesan harfiah.

TSu: ... to specialize in activities in which they have a comparative advantage.

TSa: ... untuk mengkhususkan diri dalam kegiatan yang mereka miliki keunggulan komparatifnya.

4. Calque

Teknik calque merupakan terjemahan literal dari suatu kata atau frase dalam menerjemahkan bahasa sumber ke dalam bahasa target.

TSu: government bond

TSa: obligasi pemerintah

5. Peminjaman murni (pure borrowing)

Meminjam menggunakan kata atau frasa saat menerjemahkan bahasa sumber ke dalam bahasa target tanpa melakukan perubahan apapun.

TSu: Download/Upload.

TSa: Download/Upload.

6. Transposisi (transposition)

Transposisi menggantikan kategori tata bahasa dari bahasa sumber ke dalam bahasa target, misalnya mengganti kata menjadi frasa. Teknik ini biasanya digunakan karena perbedaan tata bahasa antara TSu dan TSa.

TSu: I have no control over this condition

TSa: Saya tidak dapat mengendalikan kondisi ini

7. Modulasi

Modulasi menggantikan fokus sudut pandang atau aspek kognitif yang ada dalam TSu, baik leksikal maupun struktural.

TSu: Nobody doesn't like it.

TSa: Semua orang menyukainya.

8. Penghilangan

Memadatkan informasi yang terkandung dalam bahasa sumber ke dalam bahasa target. Pemadatan informasi tidak boleh mengubah pesan TSu.

TSu: The girl got a motorcycle accident

TSa: Perempuan itu mengalami kecelakaan

9. Eksplitasi

Dimaksudkan untuk memperjelas makna yang ada terkandung dalam TSu. TSa cenderung lebih eksplisit daripada TSu. 
TSu: it ...

TSa: (memperjelas makna pronomina it).

10. Penambahan (addition/contextual conditioning)

Penambahan menambah informasi yang pada dasarnya tidak ada pada kalimat sumber. Adanya tambahan informasi pada kalimat sasaran dimaksudkan untuk lebih memperjelas konsep yang disampaikan penulis TSu kepada pembaca. Teknik ini hanya informasi yang digunakan untuk membantu penyampaian pesan kepada pembaca. Penambahan ini tidak dapat mengubah pesan dalam bahasa sumber.

TSu: The boy came few minutes ago.

TSa: Lelaki muda itu datang beberapa menit yang lalu.

11. Deskriptif (descriptive)

Deskripsi menggantikan istilah dalam bahasa sumber dengan deskripsi dalam bahasa target. Teknik ini digunakan ketika suatu istilah dalam bahasa sumber tidak memiliki istilah dalam bahasa sasaran.

TSu: I like onde-onde.

TSa: Saya suka onde-onde, onde-onde adalah jajanan masin yang berbentuk bulat, beirisi gula merah dan disaluti parutan kelapa.

\section{Metode Penelitian}

\subsection{Metode}

Jenis penelitian ini adalah penelitian kualitatif yang didasarkan pada analisis tekstual yang melibatkan teks sumber ( $\mathrm{TSu}$ ) dan teks sasaran (TSa) serta mengadopsi salah satu model teoretis penerjemahan, yaitu model komparatif (comparative model) dengan rumusan: $\mathrm{TSu} \approx \mathrm{TSa}$, atau $\mathrm{TSa} \approx \mathrm{TSu}$.

\subsection{Data}

Data penelitian ini diambil dari abstrak dua buah artikel yang diterbitkan di International Journal of Artificial Intelligence (IJAI) pada Terbitan 6(1) tahun 2019.

Berikut data penelitian:

1. Abstrak artikel: https://doi.org/10.36079/lamintang.ijai-0601.30 [13]

Judul: Penerapan Algoritma Knuth-Morris-Pratt pada Fungsi Pencarian Dokumen untuk Sistem Informasi Administrasi Sekolah Berbasis Website

Algoritma Knuth-Morris-Pratt merupakan algoritma pencarian yang akan mencocokkan pattern atau susunan kata yang akan dicari dari kiri ke kanan pada awal teks dan kemudian menggeser susunan kata sampai susunan kata tersebut berada di ujung teks. Algoritma KMP memiliki keunggulan pencarian kecocokan pada file yang berukuran besar. Metode pengembangan sistem yang digunakan yaitu metode Rapid Application Development. Metode RAD ini adalah strategi siklus hidup yang ditujukan untuk menyediakan pengembangan yang jauh lebih cepat dan mendapatkan hasil dengan kualitas yang lebih baik dibandingkan dengan hasil yang dicapai melalui siklus tradisional. Aplikasi Sistem Informasi Administrasi Sekolah ini diharapkan dapat mengatasi permasalahan yang timbul dari proses pengendalian dokumen secara konvensional agar lebih mudah dan tepat.

Title: Applying of Knuth-Morris-Pratt Algorithm to the Document Search Function for Website-Based School Administration Information Systems

Knuth-Morris-Pratt algorithm is a search algorithm that will match the pattern or arrangement of words to be searched from left to right at the beginning of the text and then shift the order of words until the word order is at the end of the text. The KMP algorithm has the advantage of matching matches on large files. The system development method used is the Rapid Application Development method. This RAD method is a life cycle strategy aimed at providing development that is much faster and gets results with better quality compared to 
results achieved through traditional cycles. Application of School Administration Information System is expected to be able to overcome problems arising from conventional document control processes to make it easier and more precise.

2. Abstrak artikel: https://doi.org/10.36079/lamintang.ijai-0601.31 [14]

Judul: Analisis dan Penerapan Fuzzy Inference Metode Mamdani untuk Penentuan Penerima Beasiswa.

Beasiswa merupakan pemberian berupa bantuan keuangan yang diberikan kepada perorangan. Beasiswa bertujuan untuk digunakan demi keberlangsungan pendidikan yang ditempuh. SMAN 1 Parung merupakan lembaga formal milik pemerintah yang bergerak pada bidang pendidikan. SMAN 1 Parung mempunyai program beasiswa untuk siswa berprestasi yang kurang mampu. Masalah yang kerap kali terjadi yaitu tidak tepatnya pemberian beasiswa karena hanya menggunakan rata-rata nilai rapor. Berdasarkan masalah tersebut, penulis melakukan penelitian untuk menentukan penerima beasiswa menggunakan Metode Mamdani untuk Inferensi Fuzzy, dengan kriteria rata-rata nilai rapor, pendapatan orang tua, dan jumlah tanggungan orang tua. Pendekatan yang digunakan untuk menyelesaikan permasalahan penelitian melalui studi pustaka dari penelitian terdahulu tentang penentuan penerima beasiswa, teori tentang logika fuzzy metode Mamdani, kemudian menyusun tahap-tahap yang harus dilakukan dalam penelitian. Penerapan metode dan kriteri diharapkan dapat diperoleh perhitungan yang akurat sehingga menghasilkan penilaian yang akurat terhadap siswa-siswi yang berhak mendapatkan beasiswa.

Title: Analysis and Application of the Mamdani Method Fuzzy Inference System for Determining Scholarship Recipients.

Scholarships are gifts in the form of financial assistance given to individuals. Scholarships aim to be used for the sustainability of the education being pursued. SMAN 1 Parung is a formal government-owned institution which is engaged in education. SMAN 1 Parung has a scholarship program for underachievers. A problem that often occurs is the inaccuracy of scholarships because they only use an average report card grade. Based on these problems, the author conducted a study to determine the recipient of the scholarship using the Mamdani method Fuzzy Inference, with criteria for the average value of report cards, parental income, and the number of dependent parents. The approach used to solve research problems through literature studies from previous research on the determination of scholarship recipients, the theory of fuzzy logic Mamdani method, then arrange the stages that must be done in research. The application of methods and criteria is expected to be obtained by accurate calculations so as to produce an accurate assessment of students who are entitled to scholarships.

\subsection{Pemrosesan Data}

Unit analisis dalam penelitian ini adalah teknik penerjemahan yang meliputi kata, frase, klausa, dan kalimat pada dua buah artikel yang diterbitkan di International Journal of Artificial Intelligence (IJAI) pada Terbitan 6(1) tahun 2019.

Pengumpulan data dalam penelitian ini dilakukan dengan mencatat yang diadaptasi untuk membaca catatan, karena data yang akan dikumpulkan berbentuk tulisan (artikel). Teknik dasar dari sebuah teknik membaca adalah menyadap yang dalam prakteknya dilakukan dengan cara TAP, yaitu menepuk setiap kata, frase, klausa dan kalimat [8] [15].

Pada teknik TAP, naskah TSu dibaca kemudian dibandingkan dengan TSa. Isi dan maksa keduadua TSu dan TSa perlu dipahami dengan baik. Teknik triagulasi kemudian digunakan untuk mengetahui derajat validitas dan reliabilitas naskah.

Pada proses analisis data digunakan teknik analisis interaktif [16] yang terdiri atas tiga proses dalam setiap siklus, yaitu proses mereduksi data, proses penyajian data dan proses penarikan kesimpulan. 


\section{Hasil dan Pembahasan}

\subsection{Hasil}

\subsubsection{Hasil untuk Abstrak artikel: https://doi.org/10.36079/lamintang.ijai-0601.30}

Teks TSu $\approx \mathrm{TSa}$.

\begin{tabular}{|l|l|}
\hline \multicolumn{1}{|c|}{ TEKS SUMBER (TSU) } & \multicolumn{1}{|c|}{ TEKS SASARAN (TSA) } \\
\hline $\begin{array}{l}\text { Knuth-Morris-Pratt algorithm is a search algorithm } \\
\text { that will match the pattern or arrangement of words } \\
\text { to be searched from left to right at the beginning of } \\
\text { the text and then shift the order of words until the } \\
\text { word order is at the end of the text. }\end{array}$ & $\begin{array}{l}\text { Algoritma Knuth-Morris-Pratt merupakan } \\
\text { algoritma pencarian yang akan mencocokkan } \\
\text { pattern atau susunan kata yang akan dicari dari } \\
\text { kiri ke kanan pada awal teks dan kemudian } \\
\text { menggeser susunan kata sampai susunan kata } \\
\text { tersebut berada di ujung teks. }\end{array}$ \\
\hline $\begin{array}{l}\text { The KMP algorithm has the advantage of matching } \\
\text { matches on large files. }\end{array}$ & $\begin{array}{l}\text { Algoritma KMP memiliki keunggulan } \\
\text { pencarian kecocokan pada file yang berukuran } \\
\text { besar. }\end{array}$ \\
\hline $\begin{array}{l}\text { The system development method used is the Rapid } \\
\text { Application Development method. }\end{array}$ & $\begin{array}{l}\text { Metode pengembangan sistem yang digunakan } \\
\text { yaitu metode Rapid Application Development. }\end{array}$ \\
\hline $\begin{array}{l}\text { This RAD method is a life cycle strategy aimed at } \\
\text { providing development that is much faster and gets } \\
\text { results with better quality compared to results } \\
\text { achieved through traditional cycles. }\end{array}$ & $\begin{array}{l}\text { Metode RAD ini adalah strategi siklus hidup } \\
\text { yang ditujukan untuk menyediakan } \\
\text { pengembangan yang jauh lebih cepat dan } \\
\text { mendapatkan hasil dengan kualitas yang lebih } \\
\text { baik dibandingkan dengan hasil yang dicapai } \\
\text { melalui siklus tradisional. }\end{array}$ \\
\hline $\begin{array}{l}\text { Application of School Administration Information } \\
\text { System is expected to be able to overcome } \\
\text { problems arising from conventional document } \\
\text { control processes to make it easier and more } \\
\text { precise. }\end{array}$ & $\begin{array}{l}\text { Aplikasi Sistem Informasi Administrasi } \\
\text { Sekolah ini diharapkan dapat mengatasi } \\
\text { permasalahan yang timbul dari proses } \\
\text { pengendalian dokumen secara konvensional } \\
\text { agar lebih mudah dan tepat. }\end{array}$ \\
\hline
\end{tabular}

Analisis.

\begin{tabular}{|l|l|}
\hline \multicolumn{1}{|c|}{ TEKS SUMBER (TSU) } & \multicolumn{1}{c|}{ TEKS SASARAN (TSA) } \\
\hline $\begin{array}{l}\text { Knuth-Morris-Pratt } \text { algorithm is a search algorithm } \\
\text { that will match the pattern or arrangement of words } \\
\text { to be searched from left to right at the beginning of } \\
\text { the text and then shift the order of words until the } \\
\text { word order is at the end of the text. }\end{array}$ & $\begin{array}{l}\text { Algoritma Knuth-Morris-Pratt merupakan } \\
\text { algencarian yang akan mencocokkan } \\
\text { kiri ke kanan pada awal teks dan kemudian } \\
\text { menggeser susunan kata sampai susunan kata } \\
\text { tersebut berada di ujung teks. }\end{array}$ \\
\hline
\end{tabular}

\section{Knuth-Morris-Pratt $\approx$ Knuth-Morris-Pratt}

Knuth-Morris-Pratt adalah sebuah nama prosedur sistematis yang digunakan dalam bidang ilmu komputer. Kemungkinan besar pembaca TSa tidak memahami perkataan tersebut karena KnuthMorris-Pratt tidak digunakan di dalam budaya pembaca.

Menurut Wikipedia (2020, online), Knuth-Morris-Pratt is a string-matching algorithm wants to find the starting index $m$ in string $S$ [ ] that matches the search word $W$ []. Knuth-Morris-Pratt adalah prosedur sistimatis pada sebuah string yang digunakan untuk menentukan indeks awal $\mathrm{m}$ dalam sebuah string $\mathrm{S}[$ ] yang sesuai dengan kata pencarian $\mathrm{W}[$ ].

Menurut KBBI (2020, online), perkataan Knuth-Morris-Pratt tidak ditemukan dalam sistem pencarian. Oleh karena itu, dalam menerjemahkan perkataan Knuth-Morris-Pratt, teknik penerjemahan yang digunakan adalah teknik peminjaman murni (pure borrowing) yaitu meminjam menggunakan kata atau frasa bahasa sumber ke dalam bahasa target tanpa melakukan perubahan apapun.

algorithm $\approx$ algoritma

Algorithm adalah prosedur sistematis untuk memecahkan sebuah masalah matematis dalam langkahlangkah tertentu. 
Menurut Wikipedia (2020, online), algorithm is a finite sequence of well-defined, computerimplementable instructions, typically to solve a class of problems or to perform a computation. Algorithm adalah sebuah urutan/langkah-langkah khusus dari instruksi yang terdefinisi dengan baik, yang dapat diimplementasikan pada komputer dan biasanya untuk menyelesaikan masalah atau untuk melakukan proses komputasi.

Menurut KBBI (2020, online), perkataan algorithm telah dialihbahasakan menjadi algoritma. Algoritma adalah prosedur sistematis untuk memecahkan masalah matematis dalam langkah-langkah tertentu. Teknik penerjemahan yang digunakan adalah teknik peminjaman alamiah (natural borrowing) yaitu meminjam menggunakan kata atau frasa saat menerjemahkan bahasa sumber ke dalam bahasa target dengan melakukan perubahan yang tidak menghilangkan unsus-unsur TSu.

pattern $\approx$ pattern

Pattern adalah sebuah bentuk yang bisa digunakan berulang-ulang. Perkataan pattern (dalam bidang ilmu komputer) tidak ditemukan dalam budaya BSu sehingga dikhawatirkan perubahan perkataan pattern ke dalam TSu mungkin akan memberi makna lain.

Menurut Wikipedia (2020, online), a pattern is a regularity where the elements of the pattern will repeated in a predictable manner. Pattern adalah adalah sebuah keteraturan di mana elemenelemennya akan berulang dalam cara tertentu yang dapat diprediksi.

Menurut KBBI (2020, online), perkataan yang paling dekat makna dengan pattern adalah perkataan pola. Dimana pola diartikan sebagai bentuk (struktur) yang tetap, namun dalam KBBI tidak disebutkan perkataan "yang dapat diprediksi". Oleh karena itu, penulis artikel tersebut lebih memilih menggunakan perkataan pattern untuk memberi makna yang asli sesuai dengan makna yang ada dalam TSu.

Teknik penerjemahan yang digunakan adalah teknik peminjaman murni (pure borrowing) yaitu meminjam menggunakan kata atau frasa bahasa sumber ke dalam bahasa target tanpa melakukan perubahan apapun.

\begin{tabular}{|l|l|}
\hline \multicolumn{1}{|c|}{ TEKS SUMBER (TSU) } & \multicolumn{1}{|c|}{ TEKS SASARAN (TSA) } \\
\hline $\begin{array}{l}\text { The } K M P \text { algorithm has the advantage of matching } \\
\text { matches on large files. }\end{array}$ & $\begin{array}{l}\text { Algoritma } K M P \text { memiliki keunggulan } \\
\text { pencarian kecocokan pada file yang berukuran } \\
\text { besar. }\end{array}$ \\
\hline
\end{tabular}

$K M P \approx K M P$

KMP adalah singkatan dari Knuth-Morris-Pratt. Kemungkinan besar pembaca TSa tidak memahami perkataan tersebut karena $K M P$ tidak digunakan di dalam budaya pembaca.

Menurut Wikipedia (2020, online), Knuth-Morris-Pratt is a string-matching algorithm wants to find the starting index $m$ in string S[] that matches the search word W[]. Knuth-Morris-Pratt adalah prosedur sistimatis pada sebuah string yang digunakan untuk menentukan indeks awal $\mathrm{m}$ dalam sebuah string S [] yang sesuai dengan kata pencarian W []. Dan menurut KBBI (2020, online), perkataan Knuth-Morris-Pratt atau KMP tidak ditemukan dalam sistem pencarian.

Oleh karena itu, dalam menerjemahkan perkataan Knuth-Morris-Pratt (KMP), teknik penerjemahan yang digunakan adalah teknik peminjaman murni (pure borrowing) yaitu meminjam menggunakan kata atau frasa bahasa sumber ke dalam bahasa target tanpa melakukan perubahan apapun.

Untuk memperjelas makna KMP pada BSa maka peneliti mengusulkan agar penulis abstrak memberikan penjelasan tambahan pada perkataan KMP.

misalnya,

$\mathrm{TSu}$ : The KMP algorithm has the advantage of matching matches on large files.

TSa : Algoritma KMP (Knuth-Morris-Pratt adalah prosedur sistimatis pada sebuah string yang digunakan untuk menentukan indeks awal $\mathrm{m}$ dalam sebuah string $\mathrm{S}$ yang sesuai dengan kata pencarian W) memiliki keunggulan pencarian kecocokan pada file yang berukuran besar.

atau,

TSa : Algoritma KMP (singkatan dari Knuth-Morris-Pratt) memiliki keunggulan pencarian 
kecocokan pada file yang berukuran besar.

Dalam menerjemahkan perkataan Knuth-Morris-Pratt (KMP) dengan menyertakan penjelasan singkat mengenai kata pada TSu digunakan teknik penerjemahan yang disebut sebagai teknik penerjemahan deskriptif (descriptive) yaitu teknik penerjemahan dengan menggantikan istilah dalam bahasa sumber dengan deskripsi dalam bahasa target yang mana teknik ini digunakan ketika suatu istilah dalam bahasa sumber tidak memiliki istilah dalam bahasa sasaran.

Karena dalam teks ini menggunakan dua jenis teknik penerjemahan yang berbeda yaitu peminjaman murni (pure borrowing) dan deskriptif (descriptive) maka teknik penerjemahan tersebut masuk dalam kategori teknik kuplet.

\begin{tabular}{|l|l|}
\hline \multicolumn{1}{|c|}{ TEKS SUMBER (TSU) } & \multicolumn{1}{|c|}{ TEKS SASARAN (TSA) } \\
\hline $\begin{array}{l}\text { The system development method used is the Rapid } \\
\text { Application Development method. }\end{array}$ & $\begin{array}{l}\text { Metode pengembangan sistem yang digunakan } \\
\text { yaitu metode Rapid Application Development. }\end{array}$ \\
\hline
\end{tabular}

\section{System $\approx$ sistem}

Perkataan system tidak digunakan di dalam budaya pembaca.

Menurut Wikipedia (2020, online), system is a group of interacting or interrelated entities that form a unified whole. System adalah adalah sekelompok entitas yang berinteraksi atau saling terkait yang membentuk satu kesatuan yang utuh. Sedangkan menurut KBBI (2020, online), sistem adalah perangkat unsur yang secara teratur saling berkaitan sehingga membentuk suatu totalitas.

Teknik penerjemahan yang digunakan adalah teknik peminjaman alamiah (natural borrowing) yaitu meminjam menggunakan kata atau frasa saat menerjemahkan bahasa sumber ke dalam bahasa target dengan melakukan perubahan yang tidak menghilangkan unsus-unsur TSu.

\section{Rapid Application Development $\approx$ Rapid Application Development}

Kemungkinan besar pembaca TSa tidak memahami perkataan Rapid Application Development karena perkataan tersebut tidak digunakan di dalam budaya pembaca.

Menurut Wikipedia (2020, online), Rapid Application Development is an approaches to software development put less emphasis on planning and more emphasis on an adaptive process. Dikatakan bahwa, Rapid Application Development adalah pendekatan pada pengembangan sebuah perangkat lunak yang kurang menekankan pada perencanaan melainkan lebih menekankan pada proses adaptif. Sedangkan menurut KBBI (2020, online), perkataan Rapid Application Development tidak ditemukan dalam sistem pencarian.

Oleh karena itu, dalam menerjemahkan perkataan Rapid Application Development, teknik penerjemahan yang digunakan adalah teknik peminjaman murni (pure borrowing) yaitu meminjam menggunakan kata atau frasa bahasa sumber ke dalam bahasa target tanpa melakukan perubahan apapun.

Untuk memperjelas makna Rapid Application Development pada BSa maka peneliti mengusulkan agar penulis abstrak memberikan penjelasan tambahan pada perkataan Rapid Application Development.

misalnya,

$\mathrm{TSu} \quad$ : Rapid Application Development

TSa : Rapid Application Development (yang berarti, pendekatan pada pengembangan sebuah perangkat lunak yang kurang menekankan pada perencanaan melainkan lebih menekankan pada proses adaptif)

Dalam menerjemahkan perkataan Rapid Application Development dengan menyertakan penjelasan singkat mengenai kata pada TSu digunakan teknik penerjemahan yang disebut sebagai teknik penerjemahan deskriptif (descriptive) yaitu teknik penerjemahan dengan menggantikan istilah dalam bahasa sumber dengan deskripsi dalam bahasa target yang mana teknik ini digunakan ketika suatu istilah dalam bahasa sumber tidak memiliki istilah dalam bahasa sasaran.

Jika penerjemah memilih menggunakan dua jenis teknik penerjemahan yang berbeda yaitu peminjaman murni (pure borrowing) dan deskriptif (descriptive) maka teknik penerjemahan tersebut 
masuk dalam kategori teknik kuplet.

\begin{tabular}{|l|l|}
\hline \multicolumn{1}{|c|}{ TEKS SUMBER (TSU) } & \multicolumn{1}{|c|}{ TEKS SASARAN (TSA) } \\
\hline $\begin{array}{l}\text { This } R A D \text { method is a life cycle strategy aimed at } \\
\text { providing development that is much faster and gets } \\
\text { results with better quality compared to results } \\
\text { achieved through traditional cycles. }\end{array}$ & $\begin{array}{l}\text { Metode } R A D \text { ini adalah strategi siklus hidup } \\
\text { yang ditujukan untuk menyediakan } \\
\text { pengembangan yang jauh lebih cepat dan } \\
\text { mendapatkan hasil dengan kualitas yang lebih } \\
\text { baik dibandingkan dengan hasil yang dicapai } \\
\text { melalui siklus tradisional. }\end{array}$ \\
\hline
\end{tabular}

\section{$R A D \approx R A D$}

$R A D$ adalah singkatan dari Rapid Application Development. Kemungkinan besar pembaca TSa tidak memahami perkataan tersebut karena $R A D$ tidak digunakan di dalam budaya pembaca.

Menurut Wikipedia (2020, online), Rapid Application Development (RAD) is an approaches to software development put less emphasis on planning and more emphasis on an adaptive process. Dikatakan bahwa, Rapid Application Development (RAD) adalah pendekatan pada pengembangan sebuah perangkat lunak yang kurang menekankan pada perencanaan melainkan lebih menekankan pada proses adaptif. Sedangkan menurut KBBI (2020, online), perkataan Rapid Application Development atau $R A D$ tidak ditemukan dalam sistem pencarian.

Oleh karena itu, dalam menerjemahkan perkataan Rapid Application Development atau RAD, teknik penerjemahan yang digunakan adalah teknik peminjaman murni (pure borrowing) yaitu meminjam menggunakan kata atau frasa bahasa sumber ke dalam bahasa target tanpa melakukan perubahan apapun.

Untuk memperjelas makna $R A D$ pada $\mathrm{BSa}$ maka peneliti mengusulkan agar penulis abstrak memberikan penjelasan tambahan pada perkataan $R A D$.

Misalnya,

Misalnya,

TSu : Rapid Application Development

TSa : Rapid Application Development (yang berarti, pendekatan pada pengembangan sebuah perangkat lunak yang kurang menekankan pada perencanaan melainkan lebih menekankan pada proses adaptif)

atau,

TSa : RAD (singkatan dari Rapid Application Development) ....

Dalam menerjemahkan perkataan Knuth-Morris-Pratt (KMP) dengan menyertakan penjelasan singkat mengenai kata pada TSu digunakan teknik penerjemahan yang disebut sebagai teknik penerjemahan deskriptif (descriptive) yaitu teknik penerjemahan dengan menggantikan istilah dalam bahasa sumber dengan deskripsi dalam bahasa target yang mana teknik ini digunakan ketika suatu istilah dalam bahasa sumber tidak memiliki istilah dalam bahasa sasaran.

Jika penerjemah menggunakan dua jenis teknik penerjemahan yang berbeda untuk sebuah teks maka teknik penerjemahan tersebut masuk dalam kategori teknik kuplet.

\begin{tabular}{|l|l|}
\hline \multicolumn{1}{|c|}{ TEKS SUMBER (TSU) } & \multicolumn{1}{|c|}{ TEKS SASARAN (TSA) } \\
\hline $\begin{array}{l}\text { Application of School Administration Information } \\
\text { System is expected to be able to overcome problems } \\
\text { arising from conventional document control } \\
\text { processes to make it easier and more precise. }\end{array}$ & $\begin{array}{l}\text { Ani diharapkan dapat mengatasi permasalahan } \\
\text { yang timbul dari proses pengendalian dokumen } \\
\text { secara konvensional agar lebih mudah dan } \\
\text { tepat. }\end{array}$ \\
\hline
\end{tabular}


Application of School Administration Information System is expected ... :: Aplikasi Sistem Informasi Administrasi Sekolah ini diharapkan dapat ...

Kalimat "Application of School Administration Information System is expected ..." dan jika diterjemahkan secara perkataan demi perkataan adalah "Aplikasi Sistem Informasi Administrasi Sekolah diharapkan dapat ...". Kalimat tersebut mungkin membuat pembaca TSa agak bingung karena perkataan tersebut bermakna umum sedangkan dalam makna TSu perkataan tersebut mengacu pada sebuah sistem yang dibangunkan oleh penulis.

Menurut google translate (2020, online), perkataan "Application of School Administration Information System is expected ..." diterjemahkan menjadi "Aplikasi Sistem Informasi Administrasi Sekolah diharapkan dapat ...". Agar pesan TSu yang ingin disampaikan kepada pembaca bisa masuk ke dalam TSa maka perkataan "Application of School Administration Information System is expected ..." diterjemahkan sebagai "Aplikasi Sistem Informasi Administrasi Sekolah ini diharapkan dapat ..." $\rightarrow$ ada penambahan perkataan ini pada TSa, untuk memperjelas maksud TSu.

Teknik penerjemahan yang digunakan adalah teknik eksplitasi yaitu teknik penerjemahan yang dimaksudkan untuk memperjelas makna yang ada terkandung dalam TSu, dimana TSa lebih eksplisit daripada TSu.

\subsubsection{Hasil untuk Abstrak artikel: https://doi.org/10.36079/lamintang.ijai-0601.31}

Analisis teks $\mathrm{TSu} \approx \mathrm{TSa}$.

\begin{tabular}{|c|c|}
\hline TEKS SuMbER (TSU) & TEKs SASARAN (TSA) \\
\hline $\begin{array}{l}\text { Scholarships are gifts in the form of financial } \\
\text { assistance given to individuals. }\end{array}$ & $\begin{array}{l}\text { Beasiswa merupakan pemberian } \\
\text { bantuan keuangan yang diberikan } \\
\text { perorangan. }\end{array}$ \\
\hline $\begin{array}{l}\text { Scholarships aim to be used for the sustainability of } \\
\text { the education being pursued. }\end{array}$ & $\begin{array}{l}\text { Beasiswa bertujuan untuk digunakan demi } \\
\text { keberlangsungan pendidikan yang ditempuh. }\end{array}$ \\
\hline $\begin{array}{l}\text { SMAN } 1 \text { Parung is a formal government-owned } \\
\text { institution which is engaged in education. }\end{array}$ & $\begin{array}{l}\text { SMAN 1 Parung merupakan lembaga formal } \\
\text { milik pemerintah yang bergerak pada bidang } \\
\text { pendidikan. }\end{array}$ \\
\hline $\begin{array}{l}\text { SMAN } 1 \text { Parung has a scholarship program for } \\
\text { underachievers but less well off. }\end{array}$ & $\begin{array}{l}\text { SMAN } 1 \text { Parung mempunyai program beasiswa } \\
\text { untuk siswa berprestasi yang kurang mampu. }\end{array}$ \\
\hline $\begin{array}{l}\text { A problem that often occurs is the inaccuracy of } \\
\text { scholarships because they only use an average } \\
\text { report card grade. }\end{array}$ & $\begin{array}{l}\text { Masalah yang kerap kali terjadi yaitu tidak } \\
\text { tepatnya pemberian beasiswa karena hanya } \\
\text { menggunakan rata-rata nilai rapor. }\end{array}$ \\
\hline $\begin{array}{l}\text { Based on these problems, the author conducted a } \\
\text { study to determine the recipient of the scholarship } \\
\text { using the Mamdani-Type Fuzzy Inference, with } \\
\text { criteria for the average value of report cards, } \\
\text { parental income, and the number of dependent } \\
\text { parents. }\end{array}$ & $\begin{array}{l}\text { Berdasarkan masalah tersebut, penulis } \\
\text { melakukan penelitian untuk menentukan } \\
\text { penerima beasiswa menggunakan fuzzy } \\
\text { inference system metode Mamdani, dengan } \\
\text { kriteria rata-rata nilai rapor, pendapatan orang } \\
\text { tua, dan jumlah tanggungan orang tua. }\end{array}$ \\
\hline $\begin{array}{l}\text { The approach used to solve research problems } \\
\text { through literature studies from previous research on } \\
\text { the determination of scholarship recipients, the } \\
\text { theory of fuzzy logic Mamdani method, then } \\
\text { arrange the stages that must be done in research. }\end{array}$ & $\begin{array}{l}\text { Pendekatan yang digunakan untuk } \\
\text { menyelesaikan permasalahan penelitian melalui } \\
\text { studi pustaka dari penelitian terdahulu tentang } \\
\text { penentuan penerima beasiswa, teori tentang } \\
\text { logika fuzzy metode Mamdani, kemudian } \\
\text { menyusun tahap-tahap yang harus dilakukan } \\
\text { dalam penelitian. }\end{array}$ \\
\hline $\begin{array}{l}\text { The application of methods and criteria is expected } \\
\text { to be obtained by accurate calculations so as to } \\
\text { produce an accurate assessment of students who are } \\
\text { entitled to scholarships. }\end{array}$ & $\begin{array}{l}\text { Penerapan metode dan kriteri diharapkan dapat } \\
\text { diperoleh perhitungan yang akurat sehingga } \\
\text { menghasilkan penilaian yang akurat terhadap } \\
\text { siswa-siswi yang berhak mendapatkan } \\
\text { beasiswa. }\end{array}$ \\
\hline
\end{tabular}




\begin{tabular}{|l|l|}
\hline \multicolumn{1}{|c|}{ TEKS SUMBER (TSU) } & \multicolumn{1}{|c|}{ TEKS SASARAN (TSA) } \\
\hline $\begin{array}{l}\text { Scholarships are gifts in the form of financial } \\
\text { assistance given to individuals. }\end{array}$ & $\begin{array}{l}\text { Beasiswa merupakan pemberian berupa } \\
\text { bantuan keuangan yang diberikan kepada } \\
\text { perorangan. }\end{array}$ \\
\hline
\end{tabular}

Scholarships are ... $\approx$ Beasiswa merupakan ...

Kalimat "Scholarships are ..." dan jika diterjemahkan secara perkataan demi perkataan adalah "Beasiswa-beasiswa adalah ... ". Kalimat tersebut mungkin membuat pembaca TSa agak bingung karena perkataan tersebut tidak biasa digunakan dalam budaya TSa.

Menurut google translate (2020, online), perkataan "Scholarships are ..." diterjemahkan menjadi "Beasiswa adalah ... ". Agar pesan TSu yang ingin disampaikan kepada pembaca bisa masuk ke dalam TSa maka perkataan "Scholarships are ..." diterjemahkan sebagai "Beasiswa adalah ..." $\rightarrow$ ada proses memadatkan perkataan beasiswa-beasiswa (bermakna banyak) menjadi beasiswa (bermakna hanya satu).

Teknik penerjemahan yang digunakan adalah teknik transposisi (transposition) yaitu teknik penerjemahan yang menggantikan kategori tata bahasa dari bahasa sumber BSu ke dalam bahasa target $\mathrm{BSa}$, misalnya dengan mengganti kata menjadi frasa.

\begin{tabular}{|l|l|}
\hline \multicolumn{1}{|c|}{ TEKS SUMBER (TSU) } & \multicolumn{1}{|c|}{ TEKS SASARAN (TSA) } \\
\hline $\begin{array}{l}\text { SMAN 1 Parung is a formal government-owned } \\
\text { institution which is engaged in education. }\end{array}$ & $\begin{array}{l}\text { SMAN 1 Parung merupakan lembaga formal } \\
\text { milik pemerintah yang bergerak pada bidang } \\
\text { pendidikan. }\end{array}$ \\
\hline
\end{tabular}

\section{SMAN 1 Parung ... $\approx$ SMAN 1 Parung ...}

Pembaca TSa lebih memahami penggunaan perkataan SMAN 1 Parung karena perkataan tersebut ada dalam budaya TSa.

Perkataan SMAN 1 Parung adalah singkatan dari Sekolah menengah atas negeri 1 Parung. SMAN 1 Parung adalah tingkatan sekolah menengah atas yang berada di Kota Parung dengan nomor registrasi 1.

Oleh karena itu, dalam menerjemahkan perkataan SMAN 1 Parung, teknik penerjemahan yang digunakan adalah teknik peminjaman murni (pure borrowing) yaitu meminjam menggunakan kata atau frasa bahasa sumber ke dalam bahasa target tanpa melakukan perubahan apapun.

\begin{tabular}{|c|c|}
\hline TEKS SUMBER (TSU) & TEKS SASARAN (TSA) \\
\hline $\begin{array}{l}\text { A problem that often occurs is the inaccuracy of } \\
\text { scholarships because they only use an average } \\
\text { report card grade. }\end{array}$ & $\begin{array}{l}\text { Masalah yang kerap kali terjadi yaitu tidak } \\
\text { tepatnya pemberian beasiswa karena hanya } \\
\text { menggunakan rata-rata nilai rapor. }\end{array}$ \\
\hline \multicolumn{2}{|c|}{$\begin{array}{l}\text { report card grade ... } \approx \text { nilai rapor ... } \\
\text { Pembaca TSa kurang memahami penggunaan perkataan report card grade karena perkataan tersebut } \\
\text { ada dalam budaya } \mathrm{TSa} \text {. }\end{array}$} \\
\hline \multicolumn{2}{|c|}{$\begin{array}{l}\text { Menurut Wikipedia (2020, online), report card grade is grading scale to determine the quality of a } \\
\text { student's school work. Dikatakan bahwa, Kartu Pelaporan Kelas adalah kartu yang berisi skala } \\
\text { penilaian untuk menentukan kualitas pekerjaan sekolah siswa. Sedangkan menurut KBBI ( } 2020 \text {, } \\
\text { online), perkataan rapor diartikan sebabgai buku yang berisi nilai kepandaian dan prestasi belajar } \\
\text { murid di sekolah, berfungsi sebagai laporan guru kepada orang tua atau wali murid. }\end{array}$} \\
\hline $\begin{array}{l}\text { Oleh karena itu, dalam menerjemahkan perkataa } \\
\text { penerjemahan yang digunakan adalah teknik pac } \\
\text { dengan penggunaan istilah atau ungkapan yang s }\end{array}$ & $\begin{array}{l}\text { eport card grade menjadi nilai rapor, teknik } \\
\text { n lazim (establish equivalence), yaitu teknik } \\
\text { h lazim (berdasarkan kamus atau penggunaan } \\
\text { fiah (literal translation). }\end{array}$ \\
\hline
\end{tabular}




\begin{tabular}{|l|l|}
\hline \multicolumn{1}{|c|}{ TEKS SUMBER (TSU) } & \multicolumn{1}{|c|}{ TEKS SASARAN (TSA) } \\
\hline $\begin{array}{l}\text { Based on these problems, the author conducted a } \\
\text { study to determine the recipient of the scholarship } \\
\text { using the Mamdani-Type Fuzzy Inference, with } \\
\text { criteria for the average value of report cards, } \\
\text { parental income, and the number of dependent } \\
\text { marents. }\end{array}$ & $\begin{array}{l}\text { Mamdankan mantuk masalah tersebut, penulis } \\
\text { rata-rata nilai rapor, pendapatan orang tua, dan } \\
\text { jumlah tanggungan orang tua. }\end{array}$ \\
\hline
\end{tabular}

Mamdani-Type Fuzzy Inference $\approx$ Metode Mamdani untuk Inferensi Fuzzy

Tidak ditemukan perkataan Mamdani dan Fuzzy dalam budaya TSa.

Menurut Wikipedia (2020, online), Mamdani-Type Fuzzy Inference have characters like human instincts, working under the rules of linguistics and has a fuzzy algorithm that provides an approximation to enter mathematical analysis. Dikatakan bahwa Inferensi Fuzzy Tipe Mamdani memiliki karakter seperti naluri manusia, berfungsi dengan menggunakan aturan linguistik dan memiliki algoritme fuzzy yang memberikan nilai perkiraan untuk dapat di analisis matematis. Sedangkan menurut KBBI (2020, online), perkataan Mamdani dan Fuzzy tidak ditemukan.

Oleh karena itu, dalam menerjemahkan perkataan Mamdani dan Fuzzy digunakan teknik penerjemahan peminjaman murni (pure borrowing) yaitu meminjam menggunakan kata atau frasa bahasa sumber ke dalam bahasa target tanpa melakukan perubahan apapun. Sedangkan penerjemahan yang digunakan pada perkataan inference $\rightarrow$ inferensi adalah adalah teknik peminjaman alamiah (natural borrowing) yaitu meminjam menggunakan kata atau frasa saat menerjemahkan bahasa sumber ke dalam bahasa target dengan melakukan perubahan yang tidak menghilangkan unsus-unsur TSu.

Penerjemahan pada teks tersebut menggabungkan dua jenis teknik penerjemahan yang berbeda yaitu peminjaman murni (pure borrowing) dan peminjaman alamiah (natural borrowing), sehingga teknik penerjemahan tersebut masuk dalam kategori teknik kuplet.

\begin{tabular}{|l|l|}
\hline \multicolumn{1}{|c|}{ TEKS SUMBER (TSU) } & \multicolumn{1}{|c|}{ TEKS SASARAN (TSA) } \\
\hline $\begin{array}{l}\text { The application of methods and criteria is expected } \\
\text { to be obtained by accurate calculations so as to } \\
\text { produce an accurate assessment of students who are } \\
\text { entitled to scholarships. }\end{array}$ & $\begin{array}{l}\text { Penerapan metode dan kriteri diharapkan dapat } \\
\text { diperoleh perhitungan yang akurat sehingga } \\
\text { menghasilkan penilaian yang akurat terhadap } \\
\text { siswa-siswi yang berhak mendapatkan } \\
\text { beasiswa. }\end{array}$ \\
\hline
\end{tabular}

\section{students $\approx$ siswa-siswi}

Student dalam TSu mempunyai makna seluruh siswa (siswa-siswa) dan dalam budaya TSa, perkataan siswa mengarah ekpada pelajar laki-laki saja dan untuk pelajar perempuan menggunakan perkataan siswi. Sehingga perkataan students diterjemahkan sebagai siswa-siswi.

Menurut Wikipedia (2020, online), Students is plural person enrolled in a school or other educational institution and who is under learning with goals of acquiring knowledge. Dikatakan bahwa Siswasiswa adalah orang (banyak, jamak) yang terdaftar di sekolah atau sebuah lembaga pendidikan lain dan belajar dengan tujuan memperoleh pengetahuan. Sedangkan menurut KBBI (2020, online), perkataan siswa adalah berarti murid (terutama pada tingkat sekolah dasar dan menengah) atau pelajar. Sedangkan siswi adalah murid perempuan.

Oleh karena itu, dalam menerjemahkan perkataan tersebut digunakan teknik padanan budaya, dikenal sebagai teknik adaptasi (adaptation). Teknik ini dilakukan dengan mengganti unsur-unsur budaya yang ada BSu dengan unsur budaya yang mirip dan ada pada BSa. Hal tersebut bisa dilakukan karena unsur budaya dalam BSu tidak ditemukan dalam BSa, ataupun unsur budaya pada BSa tersebut lebih akrab bagi pembaca sasaran. Dalam kasus ini, pemilihan teknik adaptasi karena unsur budaya pada BSa tersebut lebih akrab bagi pembaca sasaran. 


\subsection{Pembahasan}

Dalam sub-bab ini, penulis menjelaskan jenis-jenis teknik penerjemahan yang ditemukan pada dua buah abstrak di International Journal of Artificial Intelligence (IJAI) pada Terbitan 6(1) tahun 2019.

Penulis menggunakan teknik analisis interaktif yang terdiri atas tiga proses, yaitu:

1. Proses mereduksi data

Pada proses ini, penulis memecahkan naskah menjadi per-kalimat.

2. Proses penyajian data.

Pada proses ini, penulis menyajikan data (naskah per-kalimat) ke dalam tabel dan mengidentifikasi teknik penerjemahan.

3. Proses penarikan kesimpulan.

Pada proses ini penulis mengklasifikasikannya ke dalam kategori teknik penerjemahan.

Pada Abstrak artikel dengan nomor DOI: 10.36079/lamintang.ijai-0601.30 ada empat teknik penerjemahan yang digunakan yaitu:

1. Teknik peminjaman murni (pure borrowing)

2. Teknik peminjaman alamiah (natural borrowing)

3. Teknik deskriptif (descriptive)

4. Teknik eksplitasi.

Ada dua teks yang boleh masuk kategori teknik kuplet. Teknik kuplet adalah menggambungkan dua buah teknik penerjemahan pada sebuah teks (Ma'mur, 2010). Teknik kuplet yang digunakan pada teks tersebut adalah menggabungkan teknik peminjaman murni (pure borrowing) dan deskriptif (descriptive) yang digunakan pada penerjemahan frase atau istilah.

Pada Abstrak artikel dengan nomor DOI: 10.36079/lamintang.ijai-0601.31, ada lima teknik penerjemahan yang digunakan yaitu:

1. Teknik transposisi (transposition)

2. Teknik peminjaman murni (pure borrowing)

3. Teknik padanan lazim (establish equivalence), yang mirip dengan teknik penerjemahan harfiah (literal translation).

4. Teknik peminjaman alamiah (natural borrowing)

5. Teknik adaptasi (adaptation) / padanan budaya

Ada sebuah penerjemahan pada teks yang menggabungkan dua jenis teknik penerjemahan yang berbeda yaitu peminjaman murni (pure borrowing) peminjaman alamiah (natural borrowing), sehingga teknik penerjemahan tersebut masuk dalam kategori teknik kuplet (Ma'mur, 2010).

\section{Kesimpulan}

Dalam menerjemahkan abstrak terjadi proses pemindahan informasi dari bahasa sumber (TSu) ke bahasa sasaran (TSa) dan harus menghasilkan teks yang setara. Dengan demikian, pembaca dapat memahami dan menentukan apakah perlu membaca dokumen tersebut seluruhnya.

Analisis pada karya ilmiah ini dititikberatkan pada analisis teknik penerjemahan abstrak dalam Jurnal di International Journal of Artificial Intelligence (IJAI) pada Terbitan 6(1) tahun 2019. Berdasarkan analisis permasalahan tersebut disimpulkan bahwa:

1. Dalam proses penerjemahan yang dilakukan pada teks sumber (TSu) ke dalam teks sasaran (TSa) harus mempertimbangkan aspek teoretis penerjemahan seperti aspek linguistik dan non linguistik yang terkandung di dalam teks tersebut agar mendapatkan hasil terjemahan yang sepadan/setara dan dapat difahami dengan baik oleh pembaca.

2. Salah satu faktor utama pendukung dalam proses penerjemahan yang baik dan benar adalah pengetahuan penerjemah terhadap budaya $\mathrm{BSu} / \mathrm{BSa}$. Seorang penerjemah harus mengetahui istilah-istilah yang lazim digunakan dalam budaya BSa sehingga penerjemah bisa dengan mudah menerjemahkan naskah TSu ke dalam TSa dengan baik dan benar.

3. Teknik penerjemahan yang digunakan dalam kedua-dua abstrak adalah teknik peminjaman murni (pure borrowing), teknik peminjaman alamiah (natural borrowing), teknik deskriptif (descriptive), teknik eksplitasi, teknik transposisi (transposition), teknik padanan lazim (establish equivalence), yang mirip dengan teknik penerjemahan harfiah (literal translation) serta teknik adaptasi (adaptation) / padanan budaya. 
Untuk mendapatkan hasil terjemahan yang sepadan dan dapat difahami dengan baik oleh pembaca maka perlu diperhatikan hal-hal berikut:

1. Faktor utama yang sangat mendukung dalam proses penerjemahan adalah bahwa penerjemah harus mengetahui aspek teoretis penerjemahan seperti aspek linguistik dan non linguistik. Seorang penerjemah yang baik harus mengetahui istilah-istilah dalam TSu/TSa dan budaya $\mathrm{BSu} / \mathrm{BSa}$ sehingga penerjemah bisa dengan mudah menerjemahkan naskah TSu ke dalam TSa dengan baik dan benar. Dalam naskah ini ada beberapa istilah khusus yang muncul misalnya logika fuzzy metode Mamdani, algorithm, Knuth-Morris-Pratt algorithm, dan pattern.

2. Seorang penerjemah harus mengetahui dan memahami dengan baik teknik-teknik penerjemahan sehingga seorang penerjemah bisa dengan cepat memahami kehendak naskah TSu. Hal tersebut akan memudahkan proses penerjemahan ke dalam TSu.

3. Jika ada perkataan atau frase yang mungkin tidak dipahami di dalam budaya BSa, maka disarankan untuk mencari padanan (establish equivalence, adaptation) atau memberi penjelasan tambahan (deskriftif) dalam TSa.

\section{Daftar Pustaka}

[1] Y. Kushartanti, Untung, and M. R. Lauder, "Pesona Bahasa: Langkah Awal Memahami Linguistik. Jakarta: Gramedia Pustaka Utama, 2009.

[2] R. A. Day, "How to Write Published and a Scientific Paper. Phoenix: The Oryx Press, 1998.

[3] T. R. Fitria, "TranTSuation Techniques Found in English to Indonesian Abstract Translation of Journal Edunomika 2018," ELITE Journal, vol. 5, no. 2, 2018.

[4] I. K. Trisnawati, and S. Bahri, "Strategi Penerjemahan Teks Bahasa Inggris Ke Bahasa Indonesia Calon Mahasiswa Magister Dalam Ujian Masuk Program Pascasarjana Uin ArRaniry Banda Aceh,” Getsempena English Education Journal (GEEJ), vol. 4, no. 2, 2017.

[5] I. Ma'mur, "Metode, Proses dan Strategi Menerjemah. In Tou, A.B (Ed), Orientation \& Goal of Translation Study and the Problems Within," in Proceedings of International Seminar on Translation, December 2010 (pp. 15-18). Yogyakarta: Bina Citra Pustaka, 2010.

[6] F. E. Kotambunan, and R. S. Hidayat, "Strategi Penambahan dan Penghilangan Makna: Kasus Penerjemahan Teks Hukum Bisnis dari Bahasa Inggris ke Bahasa Indonesia," Paradigma Jurnal, vol. 7, no. 2, pp. 199-212, 2017.

[7] E. A. Nida, and C. R. Taber, the Theory and Practice of Translation. Leiden: E. J. Brill, 1969.

[8] P. Newmark, a Textbook of Translation. London: Prentice Hall International, 1988.

[9] E. A. Nida and R. T. Charles, the Theory and Practice of Translation. Leiden: E. J. Brill, 1982.

[10] L. Molina and H. Albir, "Translation Technique Revisited: A Dynamic and Functionalist Approach," ERUDIT, vol. 47, no. 4, 2002.

[11] Machali, and Rohayah. Pedoman Bagi Penerjemah. Jakarta: Grasindo, 2000.

[12] Nababan, and M. Rudolf, Teori Menerjemahkan Bahasa Inggris. Yogyakarta.Pustaka Pelajar, 1999.

[13] I. Maulana, and Normalisa. "Penerapan Algoritma Knuth-Morris-Pratt pada Fungsi Pencarian Dokumen untuk Sistem Informasi Administrasi Sekolah Berbasis Website," International Journal of Artificial Intelligence, vol. 6, no. 1, pp. 1-20, doi: https://doi.org/10.36079/ lamintang.ijai-0601.30, 2019.

[14] Munawaroh, Normalisa and A. Octaviano, "Analysis and Application of the Mamdani Method Fuzzy Inference System for Determining Scholarship Recipients," International Journal of Artificial Intelligence, vol. 6, no. 1, pp. 21 - 52, doi: https://doi.org/10.36079/lamintang.ijai0601.31, 2019.

[15] Sudaryanto, Metode dan Aneka Teknik Analisis Bahasa. Yogyakarta: Duta Wacana University Press, 1993.

[16] M. B. Miles and A. M. Huberman, Qualitative Data Analysis: An Expanded Sourcebook, 2nd Edition. Newbury Park: Sage Publication, 1994. 